Indian takeover regulation - under reformed and over modified

\author{
Sandeep Parekh
}

W.P. No. 2009-11-06

November 2009

The main objective of the working paper series of the IIMA is to help faculty members, research staff and doctoral students to speedily share their research findings with professional colleagues and test their research findings at the pre-publication stage. IIMA is committed to maintain academic freedom. The opinion(s), view(s) and conclusion(s) expressed in the working paper are those of the authors and not that of IIMA.

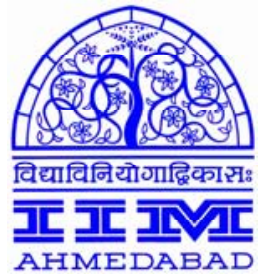

INDIAN INSTITUTE OF MANAGEMENT

AHMEDABAD-380 015

INDIA 


\title{
Indian takeover regulation - under reformed and over modified
}

\author{
Sandeep Parekh \\ Visiting Associate Faculty \\ Indian Institute of Management, Ahmedabad \\ spp@iimahd.ernet.in / sandeep.parekh@gmail.com
}

\begin{abstract}
The takeover of substantial number of shares, voting rights or control in a listed Indian company attracts the provision of SEBI (Substantial Acquisition of Shares and Takeovers) Regulations 1997. The regulations have been amended nearly 20 times since inception, though the amendments have mainly concentrated on areas which needed no amendment. At the same time a vast number of obvious problems have not been rectified in the regulations. The large number of amendments have also created requirement of a compulsory tender offer of such unnecessary complexity as to make it virtually unintelligible to even a well qualified professional.
\end{abstract}

This paper argues that the complexity in the trigger points for disclosure and tender offer introduced over the years lacks a philosophy, and most of the amendments can not only be deleted but a very simple structure can be introduced making compliance of the regulations straight forward and easy to understand by management of listed companies. Certain other areas which need amendments have also been discussed. Chief amongst these are the provisions relating to consolidation of holdings, conditional tender offers, hostility to hostile acquisitions, definitional oddities, payment of control premium in the guise of non compete fees, treatment of differential voting rights, treatment of Global Depository Receipts and disclosure enhancements.

This paper does not try to portray a particular combination of numbers as the best possible set of trigger points and compulsory acquisition numbers but advocates that whatever numbers are adopted should not be changed for several decades. Arguments that state that the changing economic condition requires constant changes with these numbers, it is argued is wrong. 


\section{INTRODUCTION}

The takeover regulations have been in existence since several decades within the listing agreement between companies and stock exchanges. In 1994 a modern set of SEBI regulations replaced the former provisions, and in 1997 the regulations were replaced by the current SEBI (Substantial Acquisition of Shares and Takeovers) Regulations 1997 (the regulations).

The 1997 regulations have been amended 19 times over the past 13 years. A vast majority of these amendments kept modifying numbers in trigger points for disclosure and compulsory tender offers contained in the regulations. To give just one example, the concept of 'creeping acquisition' exemption was modified from 2\% in 1997 to 5\% in 1998 to $10 \%$ in 2001 to 5\% in 2002 to a modified 5\% in 2008. In other words, most of them tried to second guess the wisdom of the original or amended or even subsequently amended numbers again and again. The amendment also brought in some unnecessary complexity and certain improper treatments which militate against the philosophy of equity on which the regulations were framed.

This paper first looks at the various trigger points for a compulsory tender offer which need to be simplified into a simple and easy to follow set of trigger points with a consistent philosophy. It then looks at certain persistent oddities contained in the regulations including the definition of a date, the permissibility of non compete payments and the treatment of differential voting rights. It then looks at certain regulations, specifically the proviso to regulation 12 and conditional tender offers which need to be modified or deleted to bring them in line with the purpose of the regulations. Finally the paper looks at improving the quality of disclosure filed by an acquirer on acquiring a substantial number of shares, votes or control.

\section{Trigger points for compulsory tender offer needs to be simplified.}

The takeover regulations mandating a compulsory tender offer to public shareholders is triggered on any one of the following thresholds being reached:

1.) Acquisition of shares or voting rights of $15 \%$ or more; (inclusive of the shares or voting rights already held by the acquirer or by the persons acting in concert). Thus a person holding no shares can acquire up to $14.99 \%$ voting rights and a person holding $10 \%$ could acquire up to $4.99 \%$ voting rights. The 
holding should be such as would entitle the acquirer to exercise $15 \%$ or more of the voting rights in a listed company according to Regulation 10.

2.) Regulation 10 implies that a $12 \%$ holder of voting equity cannot buy $5 \%$ without triggering the tender offer, but a $20 \%$ or a $49 \%$ holder is exempt from the tender offer on acquiring upto 5\%. This convoluted system allows creeping acquisition above 15\% but not between 10 and 15\% levels of existing shareholding. In addition 15\% is the hard boundary, if by acquiring even one share a person reaches or crosses $15 \%$, the tender offer trigger is reached.

3.) Acquisition of more than $5 \%$ of shares or voting rights in any financial year ending on $31^{\text {st }}$ March when the acquirer holds $15 \%$ or more but less than 55\% of the shares or voting rights of the company concerned would also trigger the compulsory tender offer according to Regulation 11(1). This is consistent with the listing agreement for most companies which require a minimum public shareholding of $25 \%$ because if a person with $55 \%$ acquires a single share and then is required to make a tender offer for $20 \%$, the acquirer would not be breaching the listing agreement (except by one share).

4.) Where such acquisition is for less than $5 \%$ in a year (as defined), then it is exempt in what is known as creeping acquisition exemption under the same regulation $11(1)$.

5.) Also exempt is acquisition of shares or voting rights up to $5 \%$ (one time ${ }^{\mathrm{i}}$ ), where the acquirer already owns or controls between 55 to $75 \%$ votes, if the same is the result of buy back of shares by the company or purchases are made through open market purchases as per Reg. 11(2) second proviso. This exemption is subject to an upper holding limit of $75 \%$ in case of all companies irrespective of minimum public shareholding requirement under the listing agreement.

6.) Acquisition of even a single shares or voting right where holding is already $55 \%$ or beyond the exemption given in 5) above would trigger the tender offer according to Regulation 11(2). Where a person already holds say $60 \%$ and acquires further shares, and thus makes a tender offer which is fully subscribed (i.e. 20\%), the acquirer would be holding $80 \%$ post tender offer. In such a case, if the acquirer is breaching the listing agreement which imposes a condition of public shareholding of a minimum of $25 \%$, the acquirer must bring down his holding within a time period permitted by the exchange to be again in compliance with its agreement. In the same facts where the listing 
agreement only requires a minimum $10 \%$ public shareholding, the acquirer can continue to hold the $80 \%$ shareholding. In another fact scenario of a company with a listing agreement for a minimum of $10 \%$ public shareholding, where a person is already in control of $76 \%$ voting equity, acquires further voting rights, and the tender offer for $20 \%$ takes his holding to $96 \%$, he must again divest his voting rights to below 90\% levels within a period prescribed by the exchange.

7.) In a company with a minimum public shareholding of $25 \%$, any acquirer already holding $75 \%$ or more would be prohibited from acquiring further shares as it would result in direct breach of the listing agreement except 8) below.

8.) Regulation 11(2A) read with Reg. 21 (3) provides for a special route of acquisition which does not mandate a $20 \%$ tender offer.

9.) Acquisition of direct or indirect control with or without acquisition of shares or voting rights would also trigger the tender offer requirements according to Reg. 12.

As can be seen above, there are a very large number of unnecessary and convoluted trigger points for a compulsory tender offer to be triggered. Complexity devoid of any rationale or philosophy ought to be avoided. There is a need to simplify this unnecessary complexity while keeping the philosophy of the regulations alive.

\section{Proposed trigger points}

It is proposed that there should only be one trigger on acquisition of over $5 \%$ unless the acquirer owns less than $15 \%$ shares of the target company. This would enable a person to acquire up to $15 \%$ shares i.e. up to a control figure, and not trigger a compulsory tender offer. Where a person owns any number of shares up to $50 \%$ such person should be entitled to purchase shares or voting rights up to $5 \%$ each year by way of creeping acquisition. Any acquisition over 55\% should not be allowed without a compulsory tender offer of such number of shares as would result in a post acquisition public shareholding of at least $25 \%$. This is consistent with the view of the Finance Ministry that gradually all companies should be mandated to have a minimum of $25 \%$ public shareholding ${ }^{\mathrm{ii}}$. 


\section{Consolidation of holdings}

In Reg. 11(2A), the regulations have created a special category of acquisitions called consolidations which permits a tender offer to be for less than $20 \%$ of voting shares under Reg. 11(2A). This exemption from the $20 \%$ of equity tender acquisition rule is an unnecessary loophole as there is practically no distinction between Reg. 11(2) and Reg. 11(2A). While Reg. 11(2) mandates a 20\% tender offer even on acquisition of a single share beyond creeping acquisition exemptions (typically 5\% in a year between $15 \%$ and $55 \%$ holding levels), 11(2A) seems to allow a company to make a tender offer for say $10 \%$ if the number is consistent with the minimum public shareholding prescribed in the listing agreement (which is typically $10 \%$ or $25 \%$ ).

\section{Proposal - delete the provisions relating to consolidation of holdings}

The two provisions create an unnecessary legal arbitrage between acquiring no shares and acquiring one share, where the choice would determine whether an expensive $20 \%$ tender offer is required to be made or a cheaper, say 5\%, tender offer is required. Reg. 11(2A) thus should be deleted, removing the unnecessary regulatory arbitrage. In any case if the regulations are simplified as proposed in the previous proposal, this provision would automatically stand deleted.

\section{Conditional tender offer}

Regulation 21A provides for an offer conditional upon the level of acceptance. The regulation lacks clarity. It seems to allow an offer conditional as to level of acceptance which may be less than $20 \%$ subject to the provisions of regulation $22(8)$. It also has a proviso which states that where the public offer is in pursuance of a memorandum of understanding, such MoU shall contain a condition to the effect that in case the desired level of acceptance is not received, the acquirer shall not acquire any shares under the MoU and shall rescind the offer. The use of the word "provided that where" seems to suggest that the exemption from making a minimum of $20 \%$ public offer extends to all compulsory tender offers. For instance, to take a literal view of the regulation, a person can make an offer of $20 \%$, stating that the acquirer will refuse to accept the offer if acceptance is below say $18 \%$. Where a person has acquired shares from the market and triggered the tender offer, giving such a right to the acquirer would be unfair, and in fact SEBI does not permit such an interpretation. What the regulation is trying to say is that only where acquisition of shares is by way of a memorandum of understanding which can be revoked, can a person make such a conditional offer; because there would not be any 
acquisition of voting right as the whole tender offer and the primary acquisition could be reversed altogether. Reversal of trades is impossible without disturbing the public markets if the primary acquisition is made from the markets.

\section{Proposal - recalibrate words of conditional tender offer}

Thus the conditional offer should be only available in acquisitions made by way of private agreements which can be reversed if the conditional offer is not satisfied and not in every acquisition of shares from the market which are incapable of being reversed. This is the way SEBI implements the regulation, but the position is different on a literal reading of the regulation.

\section{Friendly change of control exemption}

Control could be acquired by acquiring a small number of shares in a company with a highly dispersed shareholding. In addition, indirect control includes acquisition of control of the target company by acquisition of parent companies, whether listed or unlisted and whether in India or abroad. Acquisition of control would however not trigger the Regulations if approval by special resolution of the general body of shareholders of the target company is obtained through postal ballot. The rationale for this exemption is not clear, and it should perhaps have been deleted with the exemption for other friendly acquisitions like the preferential allotment exemption under the erstwhile exemption in Reg. 3(1)(c) ${ }^{\mathrm{iii}}$. In the year 2002, the large loophole of an exemption from a compulsory tender offer to preferential allotments was deleted. With this deletion a vast bulk of friendly takeovers which were exempted under this provision, were no longer exempt. The erstwhile exemption created a disparity between friendly acquisition and hostile acquisition. The exemption ran counter to the philosophy of the regulations, as it was wholly immaterial to the public shareholders whether the acquirer was friendly to the existing management/promoters of the company or not. In the circumstances, the exemption created regulations which had robust doors for security but which had no walls.

However, the other similar exemption in the proviso to Regulation 12 that "Provided that nothing contained herein shall apply to any change in control which takes place in pursuance to a special resolution passed by the shareholders in a general meeting” was not deleted. With the result that there continues to be a disparity between friendly change of control and hostile change of control particularly where the dominant promoter owns a substantial part of the target company to enable passage of a special resolution in a 
general meeting.

Many jurisdictions permit what is known as white wash of acquisition. This means that a compulsory tender offer is not triggered where the shareholders by special majority waive a right of compulsory tender offer. This exemption is rightly not added in India because the large number of companies with large promoter holdings would mean that the majority would subvert the interest of minority simply by passing a special resolution of shareholders which is calculated on the basis of those shareholders present and voting.

\section{Proposal - delete the exemption in Reg. 12 proviso}

The exemption is a remnant from the days when all friendly takeovers were exempt from the tender offer regulations. This was clearly recognized by SEBI as inappropriate in 2002, because it made no difference to the public shareholders whether or not the change in control brought in persons on good terms with the existing management/promoters or not. In either case the public shareholders need to be given an exit opportunity. Clearly this proviso ought to be deleted as a continuation of the private placement exemption deletion.

\section{Acquisitions must be netted off}

It was the view of Bhagwati Committee that purchases should not be netted off for calculating the acquisition of shares and votes. For example, if a person acquires 3\% shares then sells $2 \%$ and again acquire another 3\% such person would be required to make a disclosure under the recommendation of the Bhagwati Committee. However nothing in the regulations seem to point towards such an interpretation. SEBI has sometimes relied upon the committee report to calculate such position on a gross basis. This is incorrect in both principle and in practice because at no point of time the person is acquiring substantial number of shares triggering the disclosure or the tender offer norms.

\section{Proposal on netting off}

It is proposed that all acquisitions must be netted off. All positions must be calculated at a particular point of time after all sales and purchases are accounted for. It should be made clear that acquisitions are of net positions and there should not be any other interpretation possible. There is a need to put this in black and white so that there is no scope for interpretation which results in this view. 


\section{Date $31^{\text {st }}$ March definition}

The takeover regulation were amended in 2002 replacing the words 'in any period of 12 months' with 'in any financial year ending on $31^{\text {st }}$ March'. This unnecessary amendment to regulation 11 with relates to triggering of a compulsory tender offer beyond a creeping acquisition, results in a completely unfair situation. For instance, the regulations restrict a person from acquiring more than 5\% shares in a whole year i.e. 365 days. With the amendment, a person can acquire $10 \%$ shares in just 2 days between $31^{\text {st }}$ of March and $1^{\text {st }}$ of April of any year.

\section{Proposed definition of date - revert to the original definition}

The original definition ought to be brought back because though the regulations seem to indicate that no person should acquire over 5\% in a whole year, it permits acquisition of $10 \%$ in just two days. This unfair amendment ought to be reversed with the original wordings brought back.

\section{Non compete payment}

It has been seen that acquirers routinely pay control premium to select sellers to the exclusion of public shareholders subsequently in a tender offer. They do this under the provisions of regulation 20(8) - which provide for payment of non compete fee. SEBI has tried to disallow the payments in cases where there was no possible competition between the acquirer and the select sellers. However SAT has struck down SEBI's intervention in those cases. Particularly unfair is a case where the acquirer made the non compete payment to the existing promoters who had made the company virtually sick because of their incompetence ${ }^{\mathrm{iv}}$. Further many shares were sold by public charitable trusts controlled by the promoters, which were also held to be entitled to the non compete fee even though by law the public charitable trusts could not carry out any business.

\section{Proposal - delete the provision for non compete payments}

It is clear that the provision for non-compete is used for actually paying a control premium to the selling shareholders. This differential payment militates against the philosophy of fairness in the regulations. It is time that this much misused provision is deleted from the regulations and all share holders are entitled to the same price for the shares. 


\section{Treatment of differential voting rights (DVRs)}

The regulations do not provide a clear impact of the takeover regulation where a target company has several types of equity shares, particularly where they have differential voting rights. It is not clear whether the regulations mandate an acquirer to make a compulsory tender offer for $20 \%$ of total voting power or they mandate an offer for $20 \%$ of each class of equity shares. The former would be a fairer means of calculating the nature of the compulsory tender offer because an acquirer has interest in acquiring voting rights and would be interested in lower voting rights only if he gets them at a proportionately lower price. Typically since a share with $1 / 10^{\text {th }}$ voting right does not quote at $1 / 10^{\text {th }}$ of the price of the share with one voting right, such shares would be entirely useless to an acquirer.

\section{Proposal - mandate acquisition of voting rights}

In light of the above discussion, it would be fair to allow the acquirer to acquire shares as he thinks fit instead of foisting useless shares on him by way of regulations. A person buying shares with fewer voting rights compared to other shares has bought them with his eyes open that they are likely to be quoted well below the market price of the other shares and may not at all be desirable in a corporate control case. Thus no unfairness is heaped upon such person. Conversely, an acquirer should not be heaped with an unnecessary cost and forced to acquire assets which are worthless to him. This change could be effected by means of a circular or other clarification.

\section{Treatment of ADRs/GDRs}

The regulations, till Sept 2009, exempted acquisition of American/Global Depository Receipts (ADR/GDRs) from a compulsory offer under the deeply flawed view that ADRs/GDRs do not carry voting rights till converted into shares. The current regulations too assume that there are two types of ADRs/GDRs i.e.. those 'entitled to exercise voting rights' and those which do not. Reg. 3 (as amended in September 2009) states:

“(2) Nothing contained in regulation 10, regulation 11 and regulation 12 of these regulations shall apply to the acquisition of Global Depository Receipts or American Depository Receipts unless the holders thereof, -

(a) become entitled to exercise voting rights, in any manner whatsoever, on the underlying shares; or 
(b) exchange such Depository Receipts with the underlying shares carrying voting rights.”

ADRs and GDRs do carry voting rights and they are in fact receipts representing shares. They are as much shares as are Indian shares held in Indian depositories. ADR/GDRs are convenient means of holding equity of a company in another country without worrying about the logistics of buying those shares overseas using an overseas broker, converting dividends into local currency etc. For this purpose two sets of 'depositories' are used. The Indian depository which effectively holds, say 10 million, shares of that company and thus taking them out of circulation from the Indian market. Simultaneously, the foreign depository issues ADR/GDR securities for the same number (though often they are issued in a ratio - say 1 ADR to represent 2 shares) to depository receipt holders in the US market. These DR holder have all of the same rights as an Indian shareholder, for example, right to receive dividend, right to vote and right to residual value on liquidation of the company.

As far as the right to vote is concerned, it is governed by the contract between the DR holder and the depository (any financial company or even a local friendly bank could be a depository). There are four types of contract terms which could govern this contract a) the depository will take instruction from the DR holder and vote according to that wish b) the depository will vote according to what is in the best interest of the shareholders $c$ ) the depository will vote in favour of existing management d) the depository will not vote the shares. Only in the last case are votes not exercised. However, even then, the shareholder has the power to vote the shares - it is just that he has contracted away the power to someone else who will abstain from voting. If the shareholders had collectively negotiated, they could have got these rights and can always claim these by amending their agreement. This is similar to an Indian shareholder who agrees with another person (whether an individual, company, bank or institution) by way of a shareholder agreement that he will not vote the shares. The law cannot be influenced by the terms of a private agreement on voting arrangements particularly as there is no need for votes not to be exercised by the depository. The key to understanding takeover regulations is the power to exercise rather than its actual exercise.

The regulations till September 2009 treated ADR/GDRs as securities without voting rights and thus exempt them from the applicability of the tender offer requirements on 
substantial acquisition. They still maintain the dichotomy between those DRs with voting rights and those without. This is particularly perverse where the ADR/GDRs are held by the promoter group itself and they get all the rights without the obligation to make a tender offer to shareholders on large acquisitions.

\section{Proposal - treat ADRs as shares}

The amendment to regulation 3 in late September 2009 means that where voting rights are in fact exercised, the exemption will be removed. However, the exemption is still retained for cases where the DR holder gives up his rights to the depository. Having corrected three fourths of the inappropriate law, we now need to move forward and correct this perversity as well, in other words, the entire exemption for DRs should be `deleted.

\section{Other areas which need a re-look}

Materiality in indirect acquisitions: The takeover panel and SEBI have often used the wrong test when looking at change of control arising out of change of control of foreign parent of a company. They have often applied the test of materiality i.e. whether the target company is a small part of the foreign parent or not. This test is wrong because the regulations seek to protect the interest of the target shareholders, and it is immaterial to them whether they are a small part of the parent or a more substantial part.

Disclosure triggers rationalization: Regulation 7 mandates disclosure at 5, 10, 14, 54, and $74 \%$ levels of acquisitions and also every $2 \%$ purchase/sale of shares after acquiring $15 \%$ shares. This is duplicative. The disclosure triggers can be modified to 5, 10 and 15\% and every $2 \%$ purchase/sale for those holding over $15 \%$ shares.

Content of disclosures: In the formats appended to the disclosure norms of the regulations i.e. Regs. 7 and 8, too little information is sought from the acquirer. What can be added to the regulations for disclosure by the acquirer on buying substantial number of shares or voting rights is as follows:

- Purpose of acquisition? i.e. whether it is for a control motive or investment motive.

- How the acquisition will be financed? This is important for the investor to know because if the company will become a debt laden entity, a shareholder would find it an important input in deciding whether to hold onto the shares or not. 
- Whether there are any plans by the acquirer to restructure the company on a future date?

- Method of acting in concert. Where several people are acting in concert, when did the concert begin and if an agreement was signed to create a group, when the agreement was entered into.

\section{Conclusion}

This paper does not try to portray a particular combination of numbers as the best possible set of trigger points and compulsory acquisition numbers but advocates that whatever numbers are adopted should not be changed for several decades. The paper also advocates a simple regulatory regime which determines the triggers for the disclosure norms and the tender offer. Arguments that state that the changing economic condition requires constant changes with these numbers, it is argued is wrong.

There is much that needs to be worked on, and importantly, there should be no tinkering in the regulations for several decades after the regulations are cleaned up.

\footnotetext{
${ }^{\mathrm{i}}$ This is a one time exemption of $5 \%$ which can be over any period of time and in as many tranches. This is not a 5\% per annum exemption as is creeping acquisition. See SEBI circular CFD/DCR/TO/Cir01/2009/06/08 dated 6 Aug 2009.

${ }^{\text {ii }}$ Ministry of Finance’s “Discussion paper on requirement of public holding for listing”, 9 Jul 2009

iii The preferential allotment exemption contained in the now deleted Reg. 3(1)(c) exempted from the tender offer requirement any acquisition which was a result of a preferential allotment. In effect this exempted all friendly acquisitions and defeated the purpose of the regulations.

${ }^{\text {iv }}$ Cemetrum v. SEBI [2008] 83 SCL 374 (SAT)
} 